\title{
DESENVOLVIMENTO DE TUBÉRCULOS DE RABANETE EM FUNÇÃO DE DIFERENTES CONCENTRAÇÕES DE HÚMUS DE MINHOCA
}

\author{
Romário Guimarães Verçosa de Araújoํㅜ, Jessé Rafael Bento de Lima², Aleska Batista da Silva ${ }^{1}$, Gessyca Thais \\ dos Santos ${ }^{1}$, João Manoel da Silva ${ }^{3}$, Reinaldo de Alencar Paes ${ }^{4}$ \\ 'Programa de Pós-Graduação em Proteção de Plantas, Centro de Ciências Agrárias, Universidade Federal de Alagoas. \\ 2Programa de Pós-Graduação em Desenvolvimento e Meio Ambiente, Universidade Federal de Pernambuco. \\ 'Rede Nordeste de Biotecnologia, Instituto de Química e Biotecnologia, Universidade Federal de Alagoas. \\ ${ }^{4}$ Centro de Ciências Agrárias, Universidade Federal de Alagoas.
}

\begin{abstract}
RESUMO: O rabanete é uma cultura de ciclo curto e semeadura direta, a cultura pode ser prejudicada em campo por desordens fisiológicas devido a origem nutricional. Dessa forma é importante fornecer a cultura os nutrientes necessários para sua utilização, na literatura podem ser encontrados algumas recomendações para adubação mineral, porém são raros os trabalhos realizados com adubação orgânica, que apresentam vantagens como melhorar a capacidade física do solo e não ocasionar impactos ambientais como na utilização de adubos químicos. Dessa forma objetivou-se por meio desse trabalho estudar a resposta no peso e tamanho dos tubérculos de rabanete adubados húmus de minhoca em diferentes concentrações. $O$ experimento foi realizado em casa de vegetação, contendo seis tratamentos (Controle 0\%; 20\%; 40\%; 60\%; 80\% e 100\% de húmus de minhoca) e seis repetições. Foi possível verificar que a utilização da adubação orgânica ocasiona incremento no peso e diâmetro dos tubérculos de rabanete, sendo explicado a interação através de equação cúbica. É recomendado a utilização da proporção de $40 \%$ de húmus de minhoca e $60 \%$ do solo da região, pois nesse tratamento foram observadas as maiores médias para as duas variáveis estudadas.
\end{abstract}

PALAVRAS-CHAVE: Raphanus sativus, Matéria orgânica, Produção.

\section{DEVELOPMENT OF RADISH TUBER IN FUNCTION OFF DIFFERENT EARTWORMS HUMUS CONCENTRATIONS}

\begin{abstract}
Radish is a short-cycle crop and direct seeding crop, can be harmed in the field by physiological nutritional disorders. Thus it is important to provide the crop with the necessary nutrients for its use, in the literature some recommendations for mineral fertilization can be found, but there are few studies with organic fertilization, which have advantages such as improving the physical capacity of the soil and not causing environmental disorders such as in the use of chemical fertilizers. Thus, the objective of this study was to evaluate the response in the weight and size of the radish tuber fertilized with earthworm in different concentrations. The experiment was carried out in a greenhouse, containing six treatments (Control 0\%; 20\%; $40 \% ; 60 \% ; 80 \%$ and $100 \%$ earthworm humus) and six replications. It was possible to verify that the use of organic fertilization causes increase in the weight and diameter of radish tubers, being explained the interaction through cubic equation. It is recommended to use the proportion of $40 \%$ of earthworm humus and $60 \%$ of the region's soil, because in this treatment the highest averages were observed for the two studied variables.
\end{abstract}

KEYWORDS: Raphanus sativus, organic matter, production

\section{INTRODUÇÃO}

O rabanete (Raphanus sativus L.) é pertencente à Família Brassicaceae, suas raízes apresentam-se como bulbo comestível, de coloração avermelhada e sabor pungente. Dentre as hortaliças, a cultura vem apresentando uma alta demanda devido aos novos hábitos alimentares em busca de uma alimentação mais saudável. A espécie apresenta ciclo curto, em torno de 30 dias, dessa forma, possui importância agronômica como ótima opção para rotação de culturas ou plantio entre fileiras (Filgueira, 2013). 
A qualidade do sistema radicular da cultura irá depender de diversos fatores, como: temperatura, umidade e a fertilidade do solo, que irão por sua vez, influenciar de forma positiva ou negativa na qualidade de seus atributos agronômicos. De acordo com Cecilio Filho et al. (1998), um fator que pode prejudicar a produtividade comercial da cultura é a ocorrência de desordens fisiológicas de origem nutricional.

O rabanete não é uma cultura exigente em nutrientes, porém em campo está sendo verificada resposta positiva às aplicações de nutrientes (Cardoso e Hiraki, 2000). Dessa forma tem sido pesquisado no meio cientifico a resposta da cultura em relação a adubos orgânicos, buscando utilizar materiais disponíveis nas áreas de produção (Vitti et al., 2007), buscando reduzir o uso de adubos minerais e a contaminação provocada pelos mesmos ao meio ambiente (Santos, 2008).

De acordo com Finatto (2013), a utilização de práticas que ajudem a reduzir o impacto gerado, reutilizando e transformando o lixo orgânico e os resíduos de indústria em adubo, garante a produção de alimentos mais saudáveis e contribuem para um ecossistema sustentável, tornando o solo mais fértil e produtivo. A incorporação de matéria orgânica no solo além de agir de forma direta na fertilidade, também acarretam mudanças nas características físicas do solo, melhorando sua estrutura e, assim, melhorando a capacidade do solo em reter água, o que permite uma melhor distribuição do sistema radicular da planta.

Segundo Weinartner et al. (2006), o húmus é um adubo orgânico bastante estável, utilizado na lavoura como fonte de nutrientes, sendo muito rico e que pode ser produzido em grande quantidade e com baixo custo pelos produtores. Sua obtenção é realizada através da compostagem ou vermicompostagem do esterco, que poderá ser agregado a outros materiais orgânicos.

Dessa forma objetivou-se por meio desse trabalho avaliar o peso e diâmetro dos tubérculos de rabanete quando cultivadas sob diferentes doses de húmus de minhoca cultivadas em ambiente protegido.

\section{MATERIAL E MÉTODOS}

O experimento foi conduzido em casa de vegetação do Setor de Olericultura, na Unidade
Acadêmica Centro de Ciências Agrárias (CECA) da Universidade Federal de Alagoas (UFAL), Campus Delza Gitaí, Rio Largo, Alagoas (latitude 09 40' S, longitude $35^{\circ} 42^{\prime} \mathrm{W}$ e $127,00 \mathrm{~m}$ de altitude), localizado em áreas de Tabuleiros Costeiros pertencentes ao Grupo Barreiras. O clima da região, de acordo com a classificação de Köppen (1948), é do tipo As, ou seja, tropical quente e úmido.

0 delineamento experimental utilizado foi o inteiramente casualisado, apresentando seis tratamentos e seis repetições. Os tratamentos foram constituídos da aplicação de húmus de minhoca nas respectivas doses: $20 \%$; $40 \% ; 60 \% ; 80 \% ; 100 \%$ e 0 tratamento controle (sem a incorporação do adubo orgânico).

A coleta de solo para a execução do experimento foi retirada da camada arável e peneirado afim de eliminar materiais inertes e torrões. Uma amostra de solo foi enviada para o Laboratório de Solo, Água e Planta, da Universidade Federal de Alagoas, para análise química. A amostra apresentou os seguintes resultados: $\mathrm{pH}$ em água de 6,2; P: $80 \mathrm{mg} / \mathrm{dm}^{3}$; K: $113 \mathrm{mg} / \mathrm{dm}^{3}$; Ca $4,55 \mathrm{cmol}_{\mathrm{c}}$

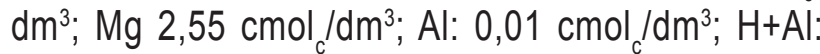
$2,70 \mathrm{cmol} / \mathrm{dm}^{3}$; CTC efetiva: $7,40 \mathrm{cmol}_{\mathrm{c}} / \mathrm{dm}^{3} ; \mathrm{CTC}$ total: $10,09 \mathrm{cmol} / \mathrm{dm}^{3}$; saturação por bases: $73 \%$; saturação de Ca; 45,1\%; saturação de $\mathrm{Mg}$ 25,3\%; e saturação de K 2,9\%.

Para o plantio foram utilizados vasos de um litro preenchidos com os substratos correspondentes a cada tratamento, sendo semeadas três sementes de rabanete (Híbrido Margaret Queen). No sétimo dia após o plantio foi realizado o desbaste das plantas, deixando aquela que apresentasse maior vigor. Durante a condução do experimento as plantas foram irrigadas diariamente.

Ao trigésimo dia após o plantio, foi realizada a colheita e quantificado o peso e diâmetro dos tubérculos de rabanete. Os resultados obtidos foram submetidos à análise de regressão através do programa estatístico Assistat (Silva e Azevedo, 2016).

\section{RESULTADOS E DISCUSSÃO}

Os componentes avaliados apresentaram diferenças significativas de acordo com o teste $F$ sob 
nível de $1 \%$ de probabilidade, entre as porcentagens de húmus de minhoca incorporado ao solo, sendo as variáveis peso e diâmetro dos tubérculos de rabanete determinadas pela regressão cúbica. Foi possível verificar que a incorporação da adubação orgânica ocasiona incremento no peso e diâmetro dos tubérculos de rabanete.

Pode ser verificado na Figura 1 em relação ao diâmetro dos tubérculos de rabanete que 0 tratamento controle apresentou uma média de $19,30 \mathrm{~cm}$, já a dose mínima de húmus de minhoca utilizada no experimento apresentou uma média de $33,70 \mathrm{~cm}$, possibilitando um incremento de aproximadamente $175 \%$. O tratamento contendo $100 \%$ de húmus de minhoca apresentou uma média de $35,66 \mathrm{~cm}$. Sendo o maior diâmetro verificado no tratamento contendo $40 \%$ do adubo orgânico, onde foi verificado uma média de $39,34 \mathrm{~cm}$. 0 valor de $\mathrm{R}^{2}$ explica que $96,34 \%$ do incremento no diâmetro dos tubérculos de rabanete foram em virtude das concentrações de húmus de minhoca determinado pela equação cúbica. 0 coeficiente de variação foi de $7,49 \%$, o que indica uma ótima precisão experimental.

Figura 1. Diâmetro dos tubérculos de rabanete em função das porcentagens de húmus de minhoca presente no substrato.

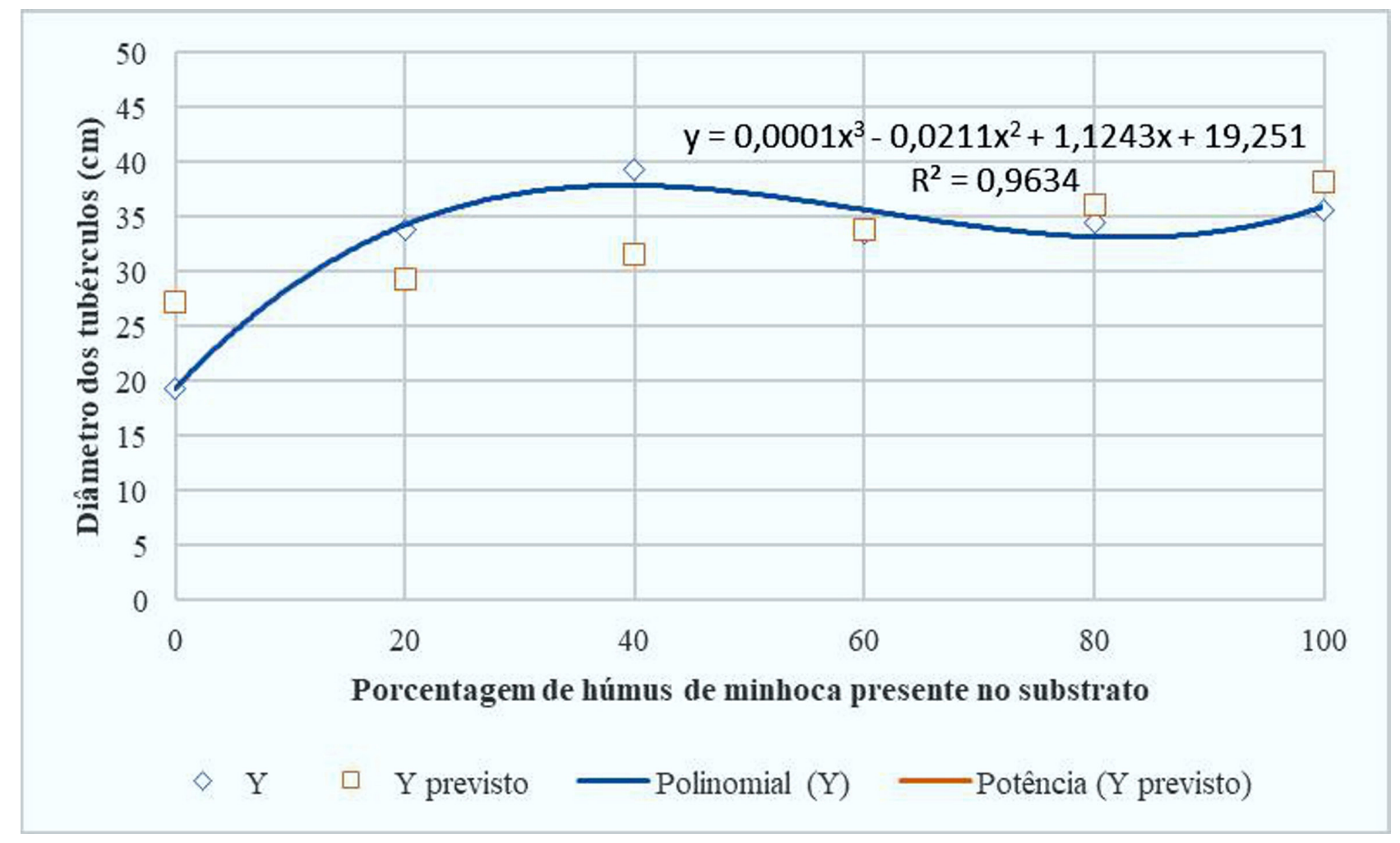

Resultados semelhantes foram obtidos por Rodrigues et al. (2013), que ao trabalhar com a aplicação em campo de 8 toneladas de esterco bovino por hectare e 30 toneladas de esterco de galinha por hectare obtiveram resposta em relação a matéria seca das plantas e diâmetro das raízes de rabanete, sendo a utilização de fontes orgânicas apresentando maiores médias em relação ao tratamento controle e adubação mineral.

Pode ser observado na Figura 2 que o peso dos tubérculos sem a incorporação do adubo orgânico foi de apenas 5,15 gramas, já com a dosagem mínima de $20 \%$ de húmus de minhoca foi verificado 23,18 gramas, um incremento de $450 \%$ no peso dos tubérculos. Ao utilizar a dose de $100 \%$ de húmus de minhoca foi observado o peso médio de 36,88 gramas. Sendo mais recomendável e rentável a utilização de $40 \%$ de húmus de minhoca e $60 \%$ de solo, onde foi verificado a maior média, apresentando 37,89 gramas. O valor de R2 indica que $91,46 \%$ do incremento no peso dos tubérculos foi em virtude das concentrações de adubo orgânico determinado pela equação cúbica. O coeficiente de variação foi de 17,58\%, o que indica uma precisão experimental próxima do regular. 
Figura 2. Peso dos tubérculos de rabanete em função das porcentagens de húmus de minhoca presente no substrato.

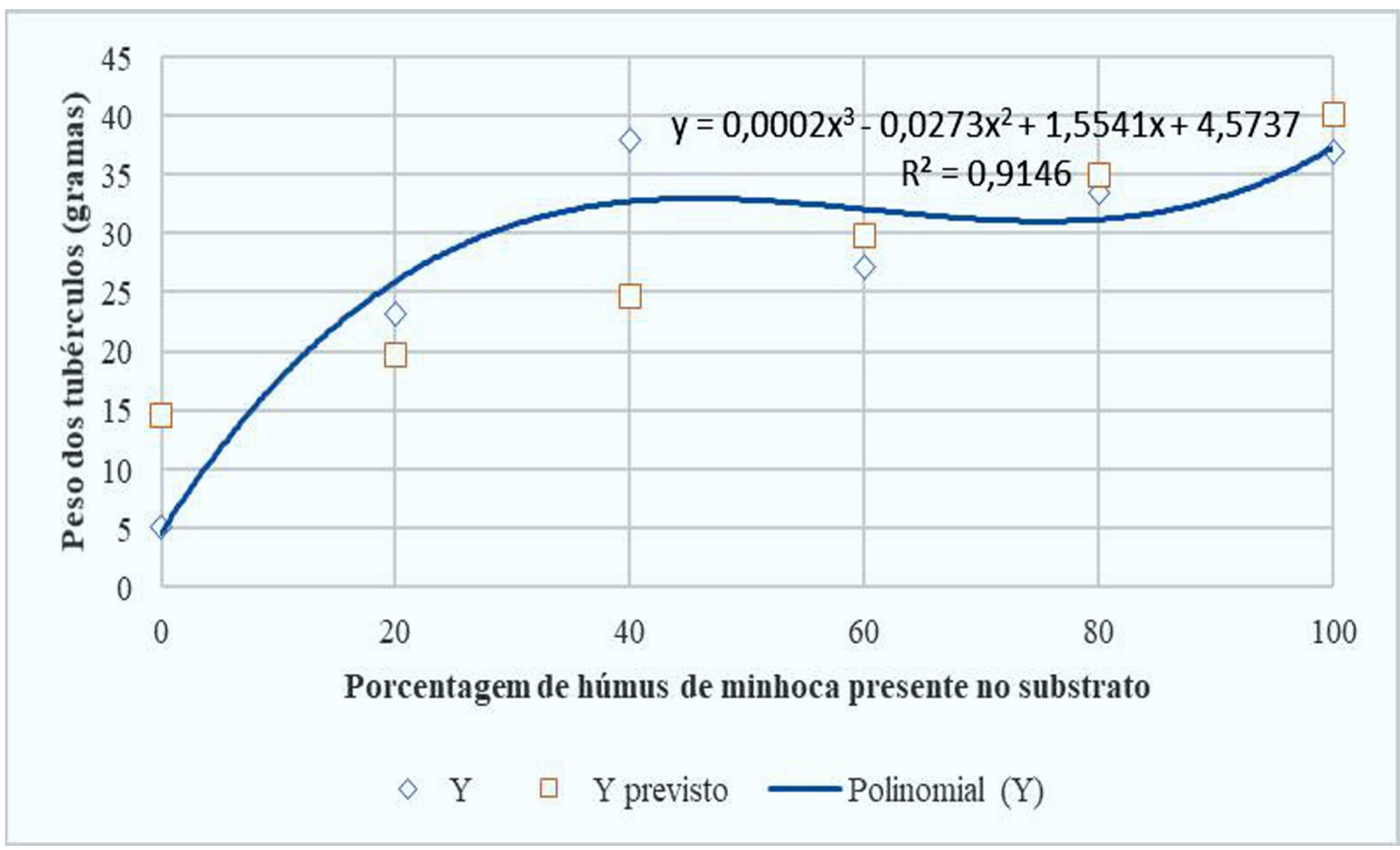

Oliveira et al. (2001), estudando a utilização de esterco bovino e húmus de minhoca como fonte de adubação orgânica para a cultura do repolho (Brassica oleracea var. capitata) híbrido Marsukase, verificaram que a incorporação de húmus de minhoca proporcionou maiores rendimentos quando comparados ao tratamento controle, ocasionando incremento tanto no peso quanto no diâmetro das cabeças de repolho.

A utilização de húmus de minhoca como fonte de adubação orgânica em cultivo protegido de rabanete contribui para o aumento no peso e diâmetro dos tubérculos, sendo ambos explicados por meio da equação cúbica. Podendo recomendar a utilização da proporção de $40 \%$ de húmus e $60 \%$ do solo da região, pois nesse tratamento foram observadas as maiores médias para as duas variáveis estudadas.

\section{REFERÊNCIAS BIBLIOGRÁFICAS}

Cardoso, A. I. I.; Hiraki, H. Avaliação do efeito de doses e de épocas de aplicação de nitrogênio em cobertura na cultura do rabanete. Anais do Congresso Brasileiro de Olericultura, 2000, p. 784-786.

Cecílio Filho, A. B.; Faquin, V.; Furtini Neto, A. E.; Souza, R. J. Deficiência nutricional e seu efeito na produção de rabanete. Científica Jaboticabal, 1998, $26,1,231-241$.

Filgueira, F. A. R. Novo manual de olericultura: agrotecnologia moderna na produção e comercialização de hortaliças. Viçosa: Editora UVF, 2013, 421p.

Koeppen, W. Climatologia: con un estudio de los climas de la tierra. Mexico, DF: Fondo de Cultura Econômica, 1948, 478p.

Oliveira, A. P.; Ferreira, D. S.; Costa, C. C.; Silva, A. F.; Alves, E. U. Uso de esterco bovino e húmus de minhoca na produção de repolho híbrido. Horticultura Brasileira, 2001, 19, 1, 70-73.

Rodrigues, J. F.; Reis, J. M. R.; Reis, M. A. Utilização de estercos em substituição a adubação mineral na cultura do rabanete. Revista Trópica: Ciências Agrárias e Biológicas, 2013, 7, 2, 160-168.

Santos, J. F. Fertilização orgânica de batata doce com doses de esterco bovino e concentrações de biofertilizantes. 2008. 93p. Tese (Doutorado em Agronomia) Universidade Federal da Paraíba, 2008. 
Vitti, M. R.; Vidal, M. B.; Morselli, T. B. G. A.; Faria, Weinartner, M. A.; Aldrighi, C. F. S.; Medeiros, C. A. J. L. C. Resposta do rabanete a adubação orgânica B. Práticas agroecológicas - Adubação orgânica. em ambiente protegido. Revista Brasileira de Pelotas: Editora Embrapa, 2006, 20p. Agroecologia, 2007, 2, 1, 1158-1161. 